\title{
The Single Administration of a Chromophore Alleviates Neural Defects in Diabetic Retinopathy
}

Volha V. Malechka, ${ }^{* \dagger}$ Jianglei Chen, ${ }^{*}$ Rui Cheng, ${ }^{*}$ Jian-xing Ma, ${ }^{*}$ and Gennadiy Moiseyev*

From the Department of Physiology, ${ }^{*}$ University of Oklahoma Health Sciences Center, Oklahoma City, Oklahoma; and the National Eye Institute, ${ }^{\dagger}$ National Institutes of Health, Bethesda, Maryland

\author{
Accepted for publication \\ March 24, 2020. \\ Address correspondence to \\ Gennadiy Moiseyev, Ph.D., \\ 941 Stanton L. Young Blvd., \\ BSEB 302, Oklahoma City, \\ OK 73104. E-mail: gennadiy- \\ moiseyev@ouhsc.edu.
}

\begin{abstract}
Diabetic retinopathy (DR) is a common complication of diabetes and a leading cause of blindness among the working-age population. Diabetic patients often experience functional deficits in dark adaptation, contrast sensitivity, and color perception before any microvascular pathologies on the fundus become detectable. Previous studies showed that the regeneration of 11-cis-retinal and visual pigment is impaired in a type 1 diabetes animal model, which negatively affects visual function at the early stage of DR. Here, Akita mice, type 1 diabetic model, were treated with the visual pigment chromophore, 9-cis-retinal. This treatment rescued a- and b-wave amplitudes of scotopic electroretinography responses, compared with vehicle-treated Akita mice. In addition, the administration of 9cis-retinal alleviated oxidative stress significantly as shown by reduced 3-nitrotyrosine levels in the retina of Akita mice. Furthermore, the 9-cis-retinal treatment decreased retinal apoptosis as shown by the terminal deoxynucleotidyl transferase-mediated dUTP nick-end labeling and DNA fragment enzymelinked immunosorbent assay. Overall, these findings showed that 9-cis-retinal administration restored visual pigment formation and decreased oxidative stress and retinal degeneration, which resulted in improved visual function in diabetic mice, suggesting that chromophore deficiency plays a causative role in visual defects in early DR. (Am J Pathol 2020, 190: 1505-1512; https://doi.org/10.1016/ j.ajpath.2020.03.009)
\end{abstract}

Diabetic retinopathy (DR) is a common complication of diabetes and a leading cause of vision impairment and blindness in adults. ${ }^{1,2}$ Traditionally, DR was considered a microvascular disease. Early studies showed that DR is characterized by microvascular abnormalities in the eye. ${ }^{3-5}$ However, accumulating evidence has suggested that visual dysfunctions and retinal neuron degeneration occur before any detectable pathologies of retinal vasculature, which contributes to vision loss in the early stages of DR. ${ }^{6-9}$ Diabetic patients with no visible alterations on the fundus of the eye demonstrate deficits in dark adaptation, contrast sensitivity, and color perception. ${ }^{10-12}$ This observation suggests that diabetic stress might directly affect the photoreceptors and retinal pigment epithelium (RPE), leading to the development of primary functional damage of the neural retina. ${ }^{13}$ The molecular basis of these functional changes of vision in early DR remains unclear and has yet to be investigated.

Vitamin A is essential for normal visual function. ${ }^{14}$ It serves as a precursor for light-sensitive 11-cis-retinal, the chromophore of visual pigments. ${ }^{15}$ Upon absorption of light, 11-cis-retinal is isomerized to all-trans-retinal, and this isomerization leads to a conformational change of opsin followed by activation of a phototransduction cascade that initiates vision. ${ }^{16}$ Normal vision depends on the constant regeneration of 11-cis-retinal in the eye. ${ }^{17}$ Regeneration of the chromophore occurs through a series of reactions of retinoids in photoreceptors and RPE, which is termed the visual cycle. ${ }^{18}$ There is evidence suggesting that vitamin A metabolism is compromised in diabetic conditions. ${ }^{19-21}$ A previous study showed that 11-cis-retinal levels are decreased in the eyes of a type 1 diabetic animal model, correlating with

\footnotetext{
Supported by NIH grants EY018659 (J.M.), EY019309 (J.M.), EY012231 (G.M. and J.M.), EY028949 (J.M.), and GM122744 (J.M.); Juvenile Diabetes Research Foundation (JDRF) grant 2-SRA-2019-711-SB (J.M.); and Oklahoma Center for the Advancement of Science and Technology (CAST) grant HR16-041 (J.M.).

Disclosures: None declared.
} 
electroretinography (ERG) decreases. ${ }^{22}$ In addition, visual pigment levels are decreased, while total opsin levels are unchanged in diabetic rat retinas, showing a decreased rhodopsin:opsin ratio and suggesting that reduced rhodopsin levels in diabetes likely are caused by impaired regeneration of 11-cisretinal. Decreased rhodopsin levels in diabetes may contribute to the decreased ERG responses, especially the a-wave amplitude in the retina. Decreased rhodopsin formation in the diabetic retina may lead to increased free opsin (unbound by 11-cis-retinal). Because an unbound opsin is constitutively active and can exhaust the phototransduction system in photoreceptors, increased free opsin in diabetic retinas may contribute to photoreceptor degeneration, exacerbating vision loss in DR. ${ }^{23}$ Based on these observations, we hypothesize that impaired regeneration of chromophore may play a causative role in visual deficits in the early DR. One approach to verify this assumption is to deliver a chromophore to the diabetic animal eye and to determine if the visual function is restored and rhodopsin generation is improved. The 11-cis-retinal is highly unstable and is not commercially available, whereas its isomer, 9-cis-retinal, is relatively stable, obtainable, and it can serve as a chromophore for visual pigments.

In this study, we investigated the effect of 9-cis-retinal administration on visual function in Akita mice, a genetic model of type 1 diabetes. The purpose of this study was to investigate the effect of exogenous 9-cis-retinal on ERG responses, retinal oxidative stress, and neuronal apoptosis. We found that treatment with 9-cis-retinal increased visual pigment levels, reduced retinal apoptosis, and improved visual function in Akita mice. Thus, the administration of a visual chromophore potentially may serve as a new approach for visual function rescue in early DR.

\section{Materials and Methods}

\section{Animals}

Male Ins2 $2^{\text {Akita/+ }}$ mice in a C57BL/6J background and wildtype C57BL/6J mice were purchased from Jackson Laboratory (Bar Harbor, ME). The care and all procedures for the animals were performed in strict agreement with the guidelines for ethical treatment and use of laboratory animals approved by the Institutional Animal Care and Use Committee of the University of Oklahoma Health Sciences Center. Animals at the age of 3 months were used for experiments throughout the study. Mice were fed ad libitum and maintained on a 12-hour light/dark cycle. Blood glucose levels were measured from tail vein samples with a glucose meter (Supplemental Figure S1) (One Touch Ultra; LifeScan, Milpitas, CA). The average blood glucose level in mice throughout the study was $430 \pm 25 \mathrm{mg} / \mathrm{dL}$.

\section{Materials for 9-cis-Retinal Injection Preparation}

Compounds 9-cis-retinal and Solutol HS15 were purchased from Sigma-Aldrich (St. Louis, MO). Before injection, 9-cis-retinal was dissolved in Solutol HS15, followed by dilution in dimethyl sulfoxide and in $1 \times$ phosphate-buffered saline. The dose of 9-cis-retinal used for intraperitoneal injection was $50 \mathrm{mg} / \mathrm{kg}$. A single intraperitoneal injection was administered to each animal under dim red light. ERG recordings and rhodopsin assay were performed 2 hours after 9-cis-retinal injection, whereas the cell death enzymelinked immunosorbent assay (ELISA) and assessment of apoptosis by terminal deoxynucleotidyl transferasemediated dUTP nick-end labeling (TUNEL) were performed 24 hours after an injection of the retinoid.

\section{Retinal Function Test with ERG}

Animals were dark-adapted for at least 16 hours before the procedure and prepared for the full-field ERG recording under dim red light. Animals were anesthetized with a solution mixture of $100 \mathrm{mg} / \mathrm{kg}$ body weight of ketamine (VetOne, Boise, ID) and $10 \mathrm{mg} / \mathrm{kg}$ body weight of xylazine (AnaSed, Shenandoah, IA) intraperitoneally. Pupils were dilated with an application of $1 \%$ cyclopentolate hydrochloride ophthalmic solution (Alcon Laboratories, Inc., Fort Worth, TX). After observable mydriasis, one drop of Goniovisc (Contacare Ophthalmics and Diagnostics, Vadodara, India) was applied to the cornea of each eye. A ground electrode was placed on a tail, a reference electrode was put in the mouth, and two gold wire loops were positioned on the corneal surface of both eyes. ERG was recorded using the Espion $\mathrm{E}^{3}$ system with a Ganzfeld ColorDome (Diagnosys LLC, Lowell, MA). Animals were placed inside the Ganzfeld sphere. A single flash of 20 candela $\times \mathrm{s} / \mathrm{m}^{2}$ intensity was applied to induce a response under fully dark-adapted conditions.

\section{Cell Death ELISA in the Retina}

The mice were sacrificed, and retinas were removed immediately. Each retina was placed in one sample tube of $100 \mu \mathrm{L}$ lysis buffer. The retina sample was processed using a plastic hand homogenizer (Eppendorf, Hamburg, Germany) for 10 short pulses. The samples were vortexed for 5 seconds, and then were incubated by rocking at room temperature for 30 minutes. The retina homogenates were centrifuged at $13,000 \times g$ for 10 minutes at $4^{\circ} \mathrm{C}$, and the supernatant was collected. Then, $20 \mu \mathrm{L}$ of each sample was tested using a DNA fragment ELISA kit (Roche, Mannheim, Germany) following the manufacturer's protocol. After that, $80 \mu \mathrm{L}$ immunoreagent was added to every well. The plate was incubated with gentle shaking for 2 hours. Then, the solution was removed, and each well was rinsed 3 times with $200 \mu \mathrm{L}$ incubation buffer. A volume of $100 \mu \mathrm{L}$ 2,2'-azino-bis-(3-ethylbenzothiazoline-6-sulfonic acid) diammonium salt solution was added to every sample and incubated for 15 minutes on a plate shaker to allow color developing. The optical density was measured at $405 \mathrm{~nm}$ using a plate reader. 


\section{Immunohistochemistry of Eyecup Sections}

Mouse eyecups were enucleated carefully and fixed with Davidson's solution for 48 hours at room temperature. The eyecups were embedded in paraffin and cut in $5-\mu \mathrm{m}$ sections. Thereafter, the cross-sections were used for staining with 3-nitrotyrosine (ab61392; Abcam, Cambridge, UK) following the manufacturer's protocol.

\section{Apoptosis Assessment in the Retina by TUNEL}

Apoptotic cells in the retina were detected with the TUNEL method. Briefly, the retina sections were deparaffinized, and then were used for TUNEL using the In Situ Cell Death Detection Kit (Roche Diagnostics, Indianapolis, IN), according to the manufacturer's instructions.

\section{Measurement of Rhodopsin Content}

All procedures were performed under dim red light. To determine the maximal rhodopsin content, animals were dark-adapted for at least 16 hours. Animals were euthanized, and their retinas were dissected. Immediately after tissue collection, each retina was homogenized in $150 \mu \mathrm{L}$ of $1 \times$ phosphate-buffered saline containing $1 \%(\mathrm{w} / \mathrm{v})$ dodecyl maltoside. Homogenates were centrifuged at $70,000 \times g$ for 1 hour. The supernatants were transferred to clean spectrophotometer cuvettes and scanned from 250 to $700 \mathrm{~nm}$ of wavelength using a DU800 spectrophotometer (Beckman Coulter, Inc., Sykesville, MD). The difference of absorbance spectra between samples before and after bleaching at $500 \mathrm{~nm}$ was used to calculate the rhodopsin content using a molar extinction coefficient of $42,000 \mathrm{~mol} / \mathrm{L}^{-1} \mathrm{~cm}^{-1}$. The data were normalized to the total volume of the supernatant and were presented as rhodopsin content per retina.

\section{Statistical Analysis}

Data were expressed as means $\pm \mathrm{SD}$ and analyzed using a two-tailed $t$-test. In all cases, a $P$ value less than 0.05 was considered statistically significant.

\section{Results}

Average blood glucose concentrations and body weights of Akita mice were measured monthly during the study. Akita mice showed high glucose concentrations throughout the study (range, $430 \pm 25 \mathrm{mg} / \mathrm{dL}$ ). ERG recordings and a rhodopsin assay were performed 2 hours after 9-cis-retinal injection, whereas the cell death ELISA and assessment of apoptosis by TUNEL were performed 24 hours after injection of the retinoid.
Visual Function in Akita Mice Is Improved after 9-cisRetinal Treatment

To evaluate the effect of 9-cis-retinal treatment on visual function, ERG was performed in two groups of 3-month-old Akita mice and one group of age- and genetic background-matched nondiabetic control mice. One group of Akita mice was treated with 9-cis-retinal $(50 \mathrm{mg} / \mathrm{kg})$, and the other group was treated with a vehicle solution. The amplitudes of a-waves and b-waves increased significantly in the group of Akita mice treated with 9-cis-retinal compared with the vehicle-treated group (Figure 1), and ERG amplitude values were restored to the range of nondiabetic control mice. These data indicate that the retinal function was impaired in Akita mice compared with nondiabetic mice, and 9-cis-retinal treatment improves visual function in diabetic eyes.

\section{Visual Pigment in Diabetic Eyes Is Increased after Treatment with 9-cis-Retinal}

Previously, it was reported that the diminished ERG response correlates with the decreased rhodopsin levels in a diabetic animal model. ${ }^{22}$ Therefore, we hypothesized that the increase of the ERG amplitude after the 9-cis-retinal treatment might be due to the increase of visual pigment levels. It has been shown by other researchers that 9-cis-retinal can be delivered to the eye, leading to an increased amount of visual pigment (isorhodopsin) in the retina of RPE65 knockout mice. ${ }^{24}$ To test this hypothesis, visual pigment levels were measured in the eyes of 9-cis-retinal and vehicle-treated mice after an intraperitoneal injection of the chromophore. Total visual pigment (rhodopsin + isorhodopsin) was extracted with detergent from dark-adapted mouse retinas and measured using a spectrophotometer. Because the shift of isorhodopsin absorption maximum from that of rhodopsin was not significant (approximately $10 \mathrm{~nm}$ ), the two different maxima could not be distinguished for the endogenous rhodopsin and isorhodopsin formed by 9-cis-retinal. The difference of absorbance spectra between bleached and unbleached visual pigments was used to quantify total visual pigment levels (Figure 2B). The amount of total visual pigment was approximately $30 \%$ higher in the retinas of 9-cis-retinaltreated animals compared with those treated with vehicle (Figure 2A).

\section{Effect of 9-cis-Retinal on the 3-Nitrotyrosine Content in the Retina}

It is well known that oxidative stress is associated with the development of DR. ${ }^{25}$ The nitric oxide level was reported to increase significantly after the onset of diabetes ${ }^{26}$ reacting with superoxide, forming peroxynitrite and nitrating biomolecules. To evaluate the effect of 9-cis-retinal on the nitrosative stress, the level of 3-nitrotyrosine, a putative marker of peroxynitrite in Akita mouse retina, was analyzed. 

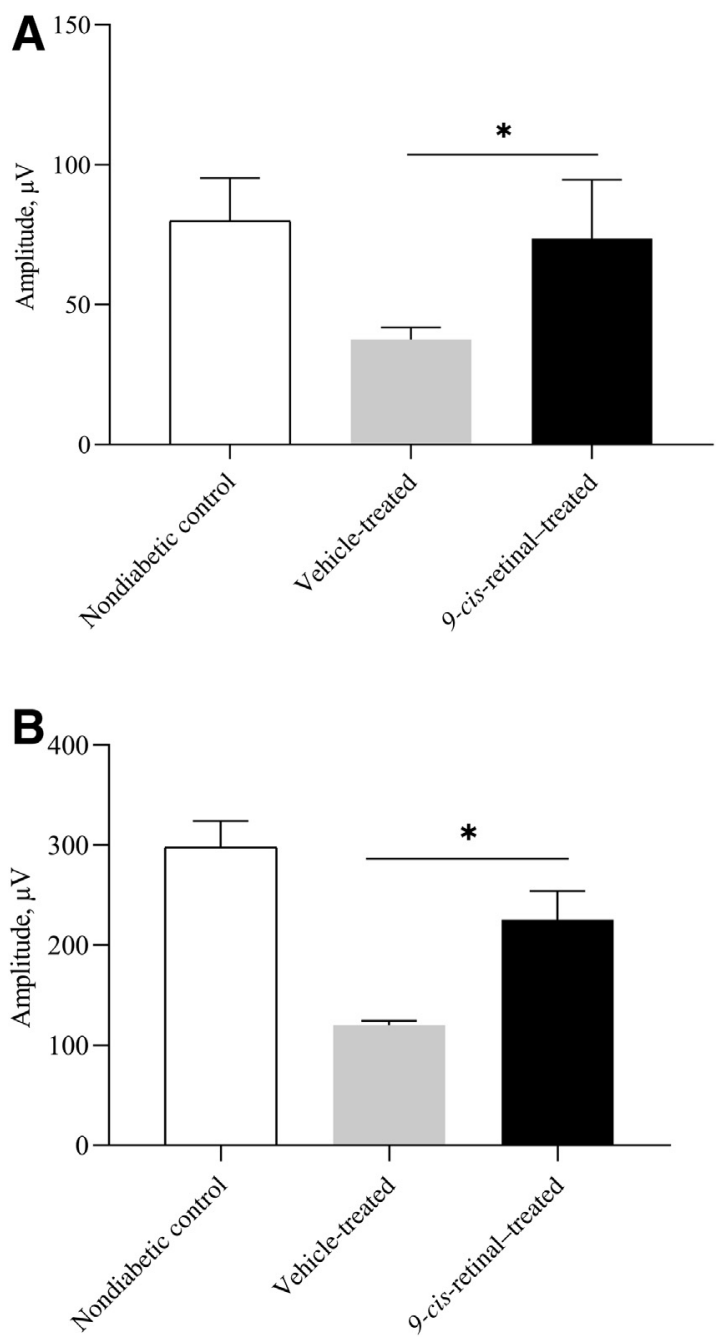

Figure 1 Analysis of retinal function in nondiabetic control and Akita mice treated with 9-cis-retinal and vehicle. Akita mice (3 months old) received an intraperitoneal injection of 9-cis retinal $(50 \mathrm{mg} / \mathrm{kg})$ or vehicle as a control. Electroretinography (ERG) recordings were performed with the bright flash at the intensity of 20 candela $\times \mathrm{s} / \mathrm{m}^{2}$ after overnight dark adaptation of mice. Amplitudes of ERG a-wave (A) and b-wave (B) in age-matched nondiabetic control and Akita mice treated with 9-cis-retinal or vehicle are presented as means \pm SD. $N=5$. ${ }^{\star} P<0.05$.

The 9-cis-retinal-treated group showed significantly lower 3-nitrotyrosine levels compared with the vehicle-treated group $(P<0.05)$, suggesting that 9-cis-retinal protects the retina from nitrosative stress induced by diabetes (Figure 3 ).

\section{Effect of 9-cis-Retinal on Cell Apoptosis in the Diabetic Retina}

Previously, it was reported that apoptosis was increased in the retina of Akita mice after 4 weeks of hyperglycemia. ${ }^{27}$ To evaluate the protective effect of 9-cis-retinal against diabetes-induced retinal apoptosis, cell death in the retinas of Akita mice were analyzed. Apoptosis in the retina was quantified using cell death ELISA by measuring cytoplasmic histone-associated DNA fragments. Retinal cell death ELISA data were normalized by tubulin levels in the retina homogenates. The treatment with 9-cis-retinal decreased the apoptosis in the retina, suggesting its protective effect on the diabetic retina (Figure 4).

To verify the data of cell death ELISA, apoptotic cells in the retina were labeled and quantified using the TUNEL method. The total number of TUNEL-positive cells was counted for each section. Treatment with 9-cis-retinal led to reduced numbers of TUNEL-positive cells in diabetic mouse retinas (Figure 5), suggesting that 9-cis-retinal treatment alleviated retinal apoptosis induced by diabetes.

\section{Discussion}

DR is a common complication of diabetes, and it remains a leading cause of vision loss. ${ }^{2}$ Recent studies have shown that DR is not only a microvascular disease of the retina,
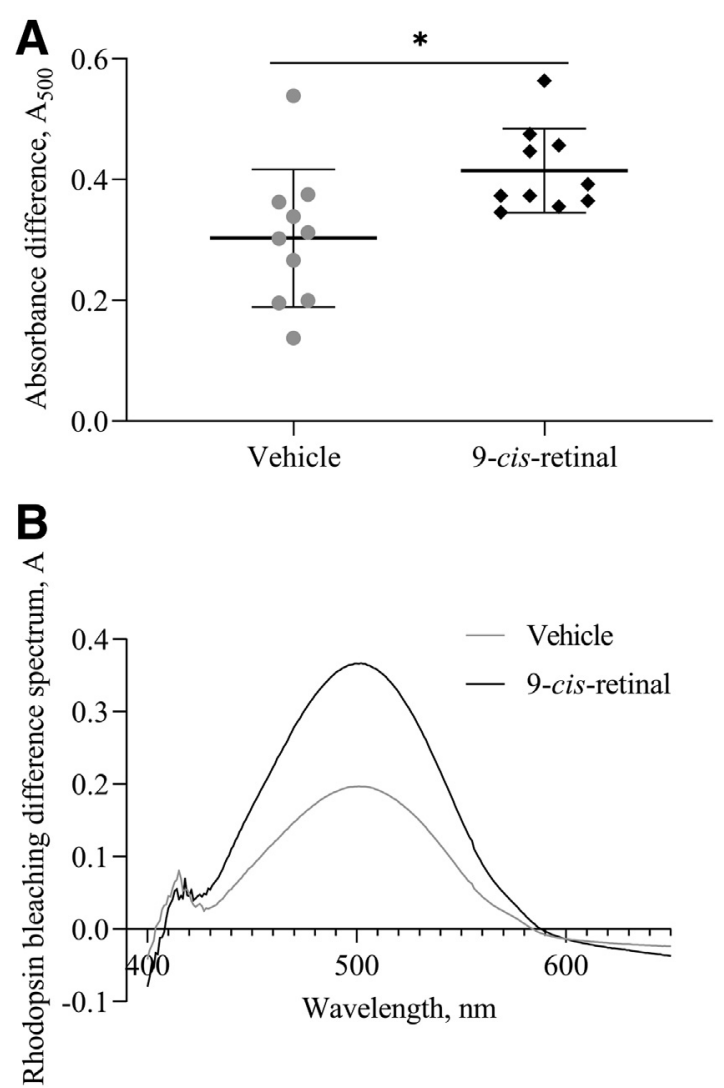

Figure 2 Increased visual pigment levels in 9-cis-retinal-treated Akita mice. Akita mice (3 months old) were given a single dose of 9-cis-retinal at $50 \mathrm{mg} / \mathrm{kg}$ intraperitoneally. The amount of pigment was analyzed as absorbance difference before and after light exposure at the wavelength of maximum absorption of rhodopsin at $500 \mathrm{~nm}$. A: Visual pigment content was measured in retinal extracts from treated and control mice by spectrophotometer. Each data point represents an average of three measurements from a single retinal extract prepared from a 9-cis-retinal-treated or control Akita mouse. B: Representative visual pigment bleaching difference spectra for mice treated with vehicle or 9-cis-retinal. The absorbance difference spectra of rhodopsin were taken from a single retinal extract prepared with one mouse eye in each group. $N=10 .{ }^{*} P<0.05$. 
A
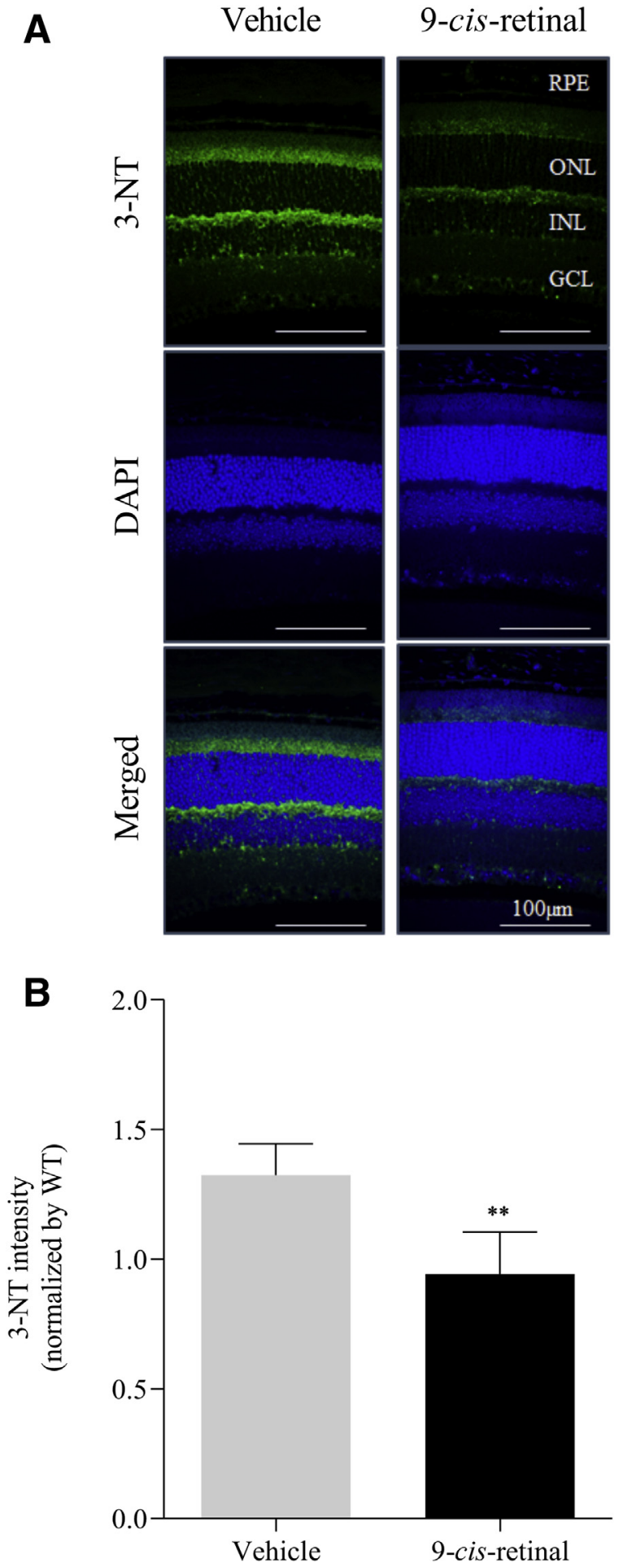

Figure 3 Effect of 9-cis-retinal treatment on 3-nitrotyrosine (3-NT) levels in the diabetic retina. Akita mice (3 months old) received an intraperitoneal injection of 9-cis-retinal or vehicle for control. Retinal sections were immunostained with an antibody for 3-NT (green), with nuclei counterstained with DAPI (blue). A: Representative photomicrographs of retinas from Akita mice treated with vehicle or 9-cis-retinal. B: The 3-NT intensities were quantified in the retinas from 9-cis-retinaltreated and vehicle-treated groups as means \pm SD. $N=6$. ${ }^{* *} P<0.01$ versus vehicle. Scale bars $=100 \mu \mathrm{m}(\mathbf{A}) . \mathrm{GCL}$, ganglion cell layer; INL, inner nuclear layer; $\mathrm{ONL}$, outer nuclear layer; RPE, retinal pigment epithelium; WT, wild-type. and that retinal function is compromised in the early stage of DR before any vascular changes become evident. ${ }^{28-31}$ However, the mechanism underlying the development of the visual deficits during early DR has yet to be investigated. Previous work showed that the amount of rhodopsin is decreased in diabetic eyes as a result of deficiency of 11-cis-retinal chromophore, which may contribute to functional deficits in the retina. ${ }^{22}$ In the present study, we showed that the treatment of diabetic mice with 9-cis-retinal, a chromophore, increased the formation of visual pigment, decreased nitrosative stress and apoptosis in the retina, and rescued retinal function in the diabetic eye.

A previous study showed that interphotoreceptor retinoidbinding protein, stimulated by retinoic acid gene 6' protein levels, were down-regulated significantly in streptozotocininduced diabetic animals, compared with nondiabetic controls. $^{22}$ Stimulated by retinoic acid gene 6' is the receptor for retinol-binding protein 4 , which is critical for the transport of vitamin $A$ to the eye from the peripheral blood. ${ }^{32}$ Interphotoreceptor retinoid-binding protein is an essential protein of the visual cycle, which facilitates the transport of retinoids between the RPE and the retina. ${ }^{33}$ Therefore, it is not surprising that the decreased expression of these two proteins in the diabetic eye is likely to impair the supply of the retina with vitamin A and to cause local vitamin A deficiency, which in turn decreases the regeneration of functional visual pigments in diabetic animals. This leads to deficient phototransduction and decreased a-waves in ERG. Moreover, the total opsin protein level is not changed in the diabetic eye, ${ }^{22}$ which suggests that a significant part of opsin remains free (ie, unbound by 11-cis-retinal chromophore). The free opsin constitutively activates the phototransduction cascade and may cause photoreceptor degeneration and increased oxidative stress. ${ }^{23,34}$ We hypothesized that exogenous chromophore may increase visual pigment generation and reduce free opsin levels, leading to the rescue of visual function in the diabetic retina. With this purpose, diabetic mice were treated with 9-cis-retinal because it can form a functional visual pigment and was used successfully as the chromophore for therapeutic application in Leber congenital amaurosis animal models. ${ }^{24}$ In the present study, a significant increase of visual pigment formation was observed in the 9cis-retinal-treated diabetic animals, compared with vehicletreated diabetic mice, suggesting that the delivered 9-cisretinal binds with the available free opsin to form visual pigments. The visual pigment isorhodopsin, formed by 9-cisretinal, is similar to rhodopsin; however, its maximum absorbance occurs at $487 \mathrm{~nm}$, which is blue-shifted from that endogenous visual pigment formed with 11-cis-retinal. However, the endogenous visual pigment in the treated mice still consists of rhodopsin with a maximum of 500-nm absorbance, and the two different absorbance peaks for isorhodopsin and rhodopsin could not be separated. Therefore, the total amount of visual pigments after the 9-cis-retinal treatment were measured. The amount of total visual pigment was found to be $30 \%$ higher after 9-cis-retinal treatment in 


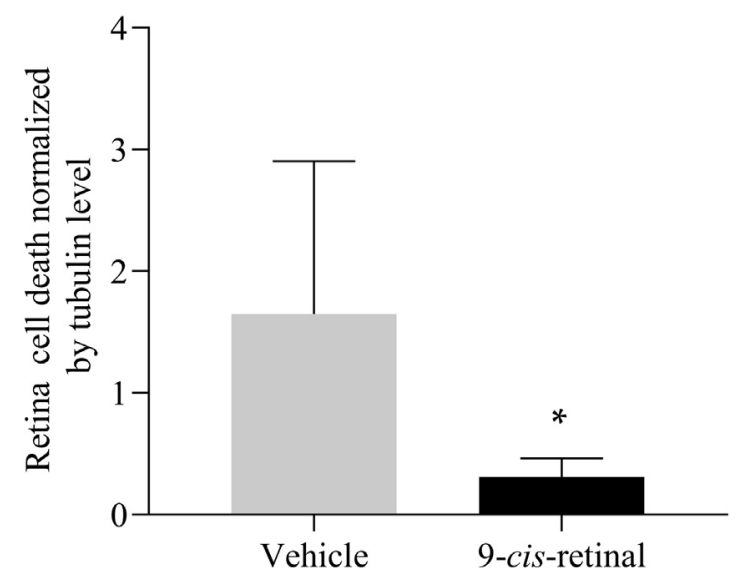

Figure 4 Inhibition of apoptosis of retinal cells by 9-cis-retinal in Akita mice. Akita mice (3 months old) received an intraperitoneal injection of 9 cis-retinal or vehicle as control. Retinal apoptosis was assessed using cell death enzyme-linked immunosorbent assay, measuring cytoplasmic histone-associated DNA fragments using an assay kit. Retinal cell death assay data were normalized by retinal tubulin levels and are shown as means \pm SD. $n=3$ in the vehicle group; $n=6$ in the 9-cis-retinal group. ${ }^{*} P<0.05$ versus vehicle.

diabetic mice over vehicle control. Previously, a $30 \%$ decrease in rhodopsin levels in streptozotocin-induced diabetic animals were found, suggesting that there is approximately $30 \%$ of unbound opsin in diabetic mice.

Based on this, we hypothesized that unbound free opsin is present in diabetic mice. Because only free opsin can form an additional photopigment as a result of the treatment with the chromophore, the measurements of visual pigment after 9-cis-retinal delivery suggest that the relative amount of free opsin in the untreated diabetic mice probably is similar to that in diabetic rats.

To evaluate the effect of 9-cis-retinal on the responses of the diabetic retina to light stimuli, the visual function of nondiabetic and Akita mice were evaluated by ERG after treatment with 9-cis-retinal. In line with previous studies, ${ }^{35}$ the a-waves and $b$-waves are decreased in the type 1 diabetic animal model, suggesting abnormal functions of photoreceptors and the inner retina. ${ }^{22}$ The group of 3-month-old Akita mice treated with 9cis-retinal has shown an improvement of both a-wave and b-wave amplitudes compared with Akita mice treated with vehicle. The percentage of increase in ERG amplitude correlated well with the percentage of increased rhodopsin content in the group treated with 9-cis-retinal. The result that supplementation of a chromophore rescued ERG responses in diabetic mice suggests that impaired generation of visual pigment contributes to the diminished electrophysiological responses in diabetic animals.

The binding of 9-cis-retinal to opsin prevents the constitutive activation of the phototransduction cascade by increased free opsin in the diabetic eye. Previously, it was reported that increased free opsin unbound by chromophore owing to interrupted regeneration of the chromophore by knockout of RPE65 or LRAT genes has deleterious effects on photoreceptors and increases oxidative stress in the retina, resulting in photoreceptor degeneration. ${ }^{34,36,37}$ Similarly, increased levels of free opsin in diabetic mice constitutively may activate the phototransduction pathway and exacerbate retinal oxidative stress induced by diabetes, leading to retinal degeneration. Excessive generation of reactive oxygen species and nitric oxide in diabetes leads to the production of peroxynitrite and the nitration of the proteins, ${ }^{26,38}$ which can result in increased apoptosis of retinal cells in DR. ${ }^{39}$ Therefore, the effects of 9-cis-retinal on the apoptosis and 3-nitrotyrosine levels in Akita mice were analyzed. The 9-cis-retinal treatment significantly decreased cell apoptosis and prevented nitrosative stress in the retina. The ameliorating effect of 9-cis-retinal found in this study corresponds with the previous report that the
A

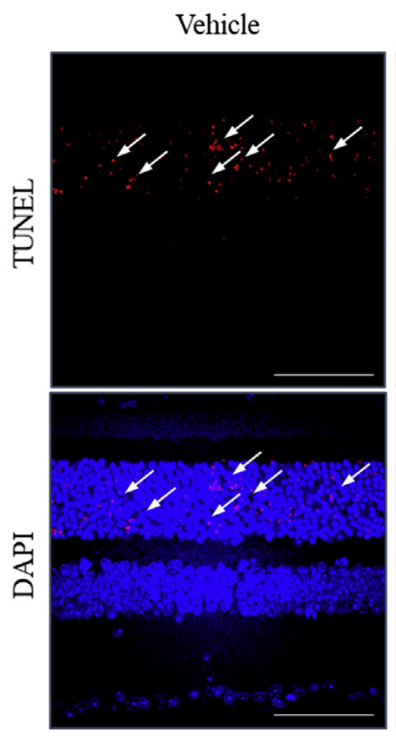

B

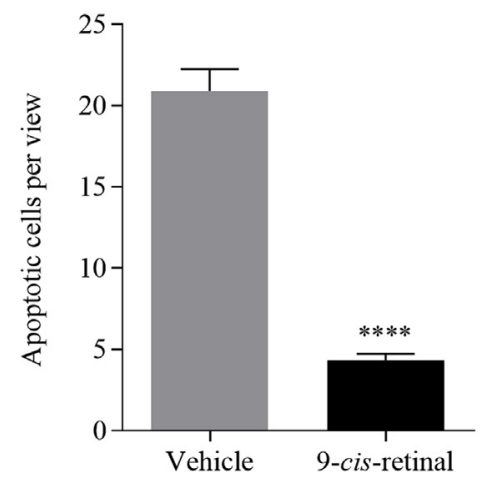

Figure 5 Effect of 9-cis-retinal on apoptosis in the retinas of Akita mice. Akita mice (3 months old) received an intraperitoneal injection of 9-cisretinal or vehicle as control. A: Apoptotic cells were labeled with the terminal deoxynucleotidyl transferase-mediated dUTP nick-end labeling (TUNEL) kit (red) with nuclei counterstained with DAPI (blue) in retinal sections. Representative fluorescence photomicrograph showing TUNEL-positive cells (arrows) in the retina from mice treated with vehicle or 9-cis-retinal. B: The number of TUNEL-positive cells was counted and compared between vehicle control and 9-cis-retinal-treated Akita mice and shown as means \pm SD. $N=6 .{ }^{* * *} P<0.0001$ versus vehicle. Scale bars $=100 \mu \mathrm{m}(\mathbf{A}) . \mathrm{GCL}$, ganglion cell layer; INL, inner nuclear layer; IPL, inner plexiform layer; $\mathrm{ONL}$, outer nuclear layer; $\mathrm{OPL}$, outer plexiform layer. 
administration of 11-cis-retinal and 9-cis-retinal to diabetic mice corrected diabetes-induced visual abnormalities as shown by transretinal recording and optokinetic tracking in diabetic animals. ${ }^{40}$ Berkowitz et al $^{40}$ did not measure the visual pigment level. Instead, they explained the ameliorative effects of 9-cis-retinal and 11-cis-retinal by the antioxidant properties of these retinoids. They also found that all-trans-retinal, which cannot form a visual pigment, also decreased superoxide generation in diabetic animals. However, they did not study the effect of all-trans-retinal on the visual function. This finding contradicts other multiple studies that showed that all-trans-retinal, conversely, increased oxidative stress and possessed high cell toxicity. $^{41,42}$ To the contrary, Liu et al proposed that the decreasing of the synthesis of 11-cis-retinal chromophore by the inhibition of the visual cycle with retinylamine treatment had a small (but significant) effect on contrast sensitivity and did not have any beneficial effect on the spatial frequency threshold. ${ }^{43}$ However, Liu et $\mathrm{al}^{43}$ used a retinoid inhibitor, retinylamine, to inhibit the visual cycle in their study. Because retinylamine is a retinoid analog and serves as a substrate for lecithin retinol acyltransferase, it may accumulate in the RPE and be metabolized to other retinoids including retinoic acid, which binds to retinoic acid receptors and regulates the expression of multiple genes. ${ }^{44}$ Thus, the results of this documented study may not be ascribed solely to the inhibition of the visual cycle.

The beneficial effect of 9-cis-retinal therapy for conditions resulting from an impaired visual cycle has shown the safety and feasibility of using this chromophore for therapeutic applications. To date, there is no available therapy to prevent the development of retinal complication in patients suffering from diabetes mellitus. This study suggests that the delivery of visual chromophore to the diabetic eye may represent a potential therapeutic strategy for the early stages of DR to prevent vision loss in diabetic patients.

In summary, these results show that the delivery of 9-cisretinal to the retina of a diabetic animal model increased the visual pigment level and ERG responses and decreased retinal apoptosis and nitrosative stress. These findings support the hypothesis that insufficient chromophore generation plays a causative role in impaired visual pigment formation, decreased ERG responses, and decreased retinal neuron apoptosis, at least in early DR. These findings may contribute to the development of a new therapeutic strategy in DR.

\section{Acknowledgment}

We thank Dr. Henry Younghwa Shin for helpful discussions.

\section{Author Contributions}

V.V.M. performed the research, analyzed the data, and wrote the manuscript; J.C. and R.C. performed experiments;
J.-X.M. designed the study, analyzed the data, and edited the manuscript; and G.M. designed the study, analyzed the data, and wrote the manuscript; G.M. is the guarantor of this work and, as such, had full access to all of the data in the study and takes responsibility for the integrity of the data and the accuracy of the data analysis.

\section{Supplemental Data}

Supplemental material for this article can be found at http://doi.org/10.1016/j.ajpath.2020.03.009.

\section{References}

1. Cheung N, Mitchell P, Wong TY: Diabetic retinopathy. Lancet 2010, 376:124-136

2. Cheloni R, Gandolfi SA, Signorelli C, Odone A: Global prevalence of diabetic retinopathy: protocol for a systematic review and metaanalysis. BMJ Open 2019, 9:e022188

3. Aiello LM, Cavallerano J: Diabetic retinopathy. Curr Ther Endocrinol Metab 1994, 5:436-446

4. Aiello LP, Gardner TW, King GL, Blankenship G, Cavallerano JD, Ferris FL 3rd, Klein R: Diabetic retinopathy. Diabetes Care 1998, 21: $143-156$

5. Crawford TN, Alfaro DV 3rd, Kerrison JB, Jablon EP: Diabetic retinopathy and angiogenesis. Curr Diabetes Rev 2009, 5:8-13

6. Sohn EH, van Dijk HW, Jiao C, Kok PH, Jeong W, Demirkaya N, Garmager A, Wit F, Kucukevcilioglu M, van Velthoven ME, DeVries JH, Mullins RF, Kuehn MH, Schlingemann RO, Sonka M, Verbraak FD, Abràmoff MD: Retinal neurodegeneration may precede microvascular changes characteristic of diabetic retinopathy in diabetes mellitus. Proc Natl Acad Sci U S A 2016, 113:E2655-E2664

7. Antonetti DA, Barber AJ, Bronson SK, Freeman WM, Gardner TW Jefferson LS, Kester M, Kimball SR, Krady JK, LaNoue KF, Norbury CC, Quinn PG, Sandirasegarane L, Simpson IA; JDRF Diabetic Retinopathy Center Group: Diabetic retinopathy: seeing beyond glucose-induced microvascular disease. Diabetes 2006, 55: 2401-2411

8. Barber AJ: A new view of diabetic retinopathy: a neurodegenerative disease of the eye. Prog Neuropsychopharmacol Biol Psychiatry 2003, 27:283-290

9. Barber AJ, Lieth E, Khin SA, Antonetti DA, Buchanan AG, Gardner TW: Neural apoptosis in the retina during experimental and human diabetes. Early onset and effect of insulin. J Clin Invest 1998, 102:783-791

10. Sokol S, Moskowitz A, Skarf B, Evans R, Molitch M, Senior B: Contrast sensitivity in diabetics with and without background retinopathy. Arch Ophthalmol 1985, 103:51-54

11. Zeng Y, Cao D, Yu H, Yang D, Zhuang X, Hu Y, Li J, Yang J, Wu Q, Liu B, Zhang L: Early retinal neurovascular impairment in patients with diabetes without clinically detectable retinopathy. $\mathrm{Br} \mathrm{J}$ Ophthalmol 2019, 103:1747-1752

12. Gregori B, Galie E, Pro S, Clementi A, Accornero C: Luminance and chromatic visual evoked potentials in type I and type II diabetes: relationships with peripheral neuropathy. Neurol Sci 2006, 27: 323-327

13. Lieth E, Gardner TW, Barber AJ, Antonetti DA; Penn State Retina Research Group: Retinal neurodegeneration: early pathology in diabetes. Clin Exp Ophthalmol 2000, 28:3-8

14. Elder JH: Effectiveness of vitamin A in the treatment of defective color vision. Science 1943, 97:561-562 
15. Wald G: The synthesis from vitamin A1 of retinene 1 and of a new $545 \mathrm{~m}$-mu chromogen yielding light-sensitive products. J Gen Physiol 1948, 31:489-504

16. Wald G: Molecular basis of visual excitation. Science 1968, 162: 230-239

17. Crouch R, Katz S: The effect of retinal isomers on the VER and ERG of vitamin A deprived rats. Vis Res 1980, 20:109-115

18. Kiser PD, Golczak M, Palczewski K: Chemistry of the retinoid (visual) cycle. Chem Rev 2014, 114:194-232

19. Basu TK, Tze WJ, Leichter J: Serum vitamin A and retinol-binding protein in patients with insulin-dependent diabetes mellitus. Am J Clin Nutr 1989, 50:329-331

20. Baena RM, Campoy C, Bayes R, Blanca E, Fernandez JM, MolinaFont JA: Vitamin A, retinol binding protein and lipids in type 1 diabetes mellitus. Eur J Clin Nutr 2002, 56:44-50

21. Forga L, Bolado F, Goni MJ, Tamayo I, Ibanez B, Prieto C: Low serum levels of prealbumin, retinol binding protein, and retinol are frequent in adult type 1 diabetic patients. J Diabetes Res 2016, 2016: 2532108

22. Malechka VV, Moiseyev G, Takahashi Y, Shin Y, Ma JX: Impaired rhodopsin generation in the rat model of diabetic retinopathy. Am J Pathol 2017, 187:2222-2231

23. Woodruff ML, Wang Z, Chung HY, Redmond TM, Fain GL, Lem J: Spontaneous activity of opsin apoprotein is a cause of Leber congenital amaurosis. Nat Genet 2003, 35:158-164

24. Van Hooser JP, Aleman TS, He YG, Cideciyan AV, Kuksa V, Pittler SJ, Stone EM, Jacobson SG, Palczewski K: Rapid restoration of visual pigment and function with oral retinoid in a mouse model of childhood blindness. Proc Natl Acad Sci U S A 2000, 97:8623-8628

25. Newsholme P, Cruzat VF, Keane KN, Carlessi R, de Bittencourt PI Jr: Molecular mechanisms of ROS production and oxidative stress in diabetes. Biochem J 2016, 473:4527-4550

26. Hernandez-Ramirez E, Sanchez-Chavez G, Estrella-Salazar LA, Salceda R: Nitrosative stress in the rat retina at the onset of streptozotocin-induced diabetes. Cell Physiol Biochem 2017, 42: $2353-2363$

27. Barber AJ, Antonetti DA, Kern TS, Reiter CE, Soans RS, Krady JK, Levison SW, Gardner TW, Bronson SK: The Ins2Akita mouse as a model of early retinal complications in diabetes. Invest Ophthalmol Vis Sci 2005, 46:2210-2218

28. Aung MH, Kim MK, Olson DE, Thule PM, Pardue MT: Early visual deficits in streptozotocin-induced diabetic long evans rats. Invest Ophthalmol Vis Sci 2013, 54:1370-1377

29. Jackson GR, Scott IU, Quillen DA, Walter LE, Gardner TW: Inner retinal visual dysfunction is a sensitive marker of non-proliferative diabetic retinopathy. Br J Ophthalmol 2012, 96:699-703

30. Phipps JA, Fletcher EL, Vingrys AJ: Paired-flash identification of rod and cone dysfunction in the diabetic rat. Invest Ophthalmol Vis Sci 2004, 45:4592-4600
31. Bearse MA Jr, Adams AJ, Han Y, Schneck ME, Ng J, BronsonCastain K, Barez S: A multifocal electroretinogram model predicting the development of diabetic retinopathy. Prog Retin Eye Res 2006, 25:425-448

32. Ruiz A, Mark M, Jacobs H, Klopfenstein M, Hu J, Lloyd M, Habib S, Tosha C, Radu RA, Ghyselinck NB, Nusinowitz S, Bok D: Retinoid content, visual responses, and ocular morphology are compromised in the retinas of mice lacking the retinol-binding protein receptor, STRA6. Invest Ophthalmol Vis Sci 2012, 53:3027-3039

33. Crouch RK, Hazard ES, Lind T, Wiggert B, Chader G, Corson DW: Interphotoreceptor retinoid-binding protein and alpha-tocopherol preserve the isomeric and oxidation state of retinol. Photochem Photobiol 1992, 56:251-255

34. Yang F, Ma H, Boye SL, Hauswirth WW, Ding XQ: Overexpression of type 3 iodothyronine deiodinase reduces cone death in the leber congenital amaurosis model mice. Adv Exp Med Biol 2018, 1074: 125-131

35. Phipps JA, Yee P, Fletcher EL, Vingrys AJ: Rod photoreceptor dysfunction in diabetes: activation, deactivation, and dark adaptation. Invest Ophthalmol Vis Sci 2006, 47:3187-3194

36. Fan J, Rohrer B, Frederick JM, Baehr W, Crouch RK: Rpe65-/- and Lrat-/- mice: comparable models of leber congenital amaurosis. Invest Ophthalmol Vis Sci 2008, 49:2384-2389

37. Fan J, Woodruff ML, Cilluffo MC, Crouch RK, Fain GL: Opsin activation of transduction in the rods of dark-reared Rpe65 knockout mice. J Physiol 2005, 568:83-95

38. Ceriello A, Mercuri F, Quagliaro L, Assaloni R, Motz E, Tonutti L, Taboga C: Detection of nitrotyrosine in the diabetic plasma: evidence of oxidative stress. Diabetologia 2001, 44:834-838

39. Barber AJ, Gardner TW, Abcouwer SF: The significance of vascular and neural apoptosis to the pathology of diabetic retinopathy. Invest Ophthalmol Vis Sci 2011, 52:1156-1163

40. Berkowitz BA, Kern TS, Bissig D, Patel P, Bhatia A, Kefalov VJ, Roberts R: Systemic retinaldehyde treatment corrects retinal oxidative stress, rod dysfunction, and impaired visual performance in diabetic mice. Invest Ophthalmol Vis Sci 2015, 56:6294-6303

41. Lochner JE, Badwey JA, Horn W, Karnovsky ML: All-trans-retinal stimulates superoxide release and phospholipase C activity in neutrophils without significantly blocking protein kinase C. Proc Natl Acad Sci U S A 1986, 83:7673-7677

42. Sawada O, Perusek L, Kohno H, Howell SJ, Maeda A, Matsuyama S, Maeda T: All-trans-retinal induces bax activation via DNA damage to mediate retinal cell apoptosis. Exp Eye Res 2014, 123:27-36

43. Liu H, Tang J, Du Y, Lee CA, Golczak M, Muthusamy A, Antonetti DA, Veenstra AA, Amengual J, von Lintig J, Palczewski K, Kern TS: Retinylamine benefits early diabetic retinopathy in mice. J Biol Chem 2015, 290:21568-21579

44. Cvekl A, Wang WL: Retinoic acid signaling in mammalian eye development. Exp Eye Res 2009, 89:280-291 